\title{
Dynamics in composition and size-class distribution of humic substances in profundal sediments of Lake Constance
}

\author{
Andreas Kappler, Rong Ji, Bernhard Schink, Andreas Brune* \\ Fachbereich Biologie, Lehrstuhl für Mikrobielle Ökologie und Limnologie, Universität Konstanz, \\ Fach M654, 78457 Konstanz, Germany
}

Received 25 May 2000; accepted 1 November 2000

(returned to author for revision 6 July 2000)

\begin{abstract}
Organic matter from profundal lake sediments was fractionated and analyzed with high depth resolution, and the size-class distribution of humic substances was determined by gel-permeation chromatography. Together with a depthdependent increase of the thermal stability of the organic matter and an increasing $\mathrm{C} / \mathrm{N}$ atomic ratio of the humic acids, the size-distribution patterns of different fractions indicated an increasing degree of humification with depth. The main stabilization processes occurred in the surface layer $(0-2 \mathrm{~cm}$ depth), which is clearly distinguished from the deeper sediment. The depth profiles also indicated that humification in lake sediments consists of simultaneous degradation and polymerization processes. (C) 2001 Elsevier Science Ltd. All rights reserved.
\end{abstract}

Keywords: Lake sediment; Size-class distribution; Humic substances; Humification processes

\section{Introduction}

The organic matter in lakewater typically consists of a complex mixture of aromatic components, carbohydrates, proteins, lipids, and other compounds, stemming from autochthonous sources, and to a varying extent from allochthonous sources (Ishiwatari, 1985; Meyers and Ishiwatari, 1993; McKnight and Aiken, 1998). Although an important portion of this organic matter is degraded chemically and biologically within the water column, a significant portion $(10-60 \%)$ reaches the sediment surface (Steinberg and Muenster, 1985), where it is subjected to further chemical and biological transformations.

In contrast to littoral sediments, which are strongly influenced by bioturbation and wave movement, profundal sediments are only marginally influenced by

\footnotetext{
* Corresponding author. Tel.: +49-7531-883282; fax: +497531-882966.

E-mail address: andreas.brune@uni-konstanz.de (A. Brune).
}

mixing and resuspension effects, resulting in a stratification of chemical, biological, and physical parameters (Zehnder and Stumm, 1988). Due to the high respiration activity, oxygen penetrates only the upper few millimeters (Zehnder and Stumm, 1988; Schink, 1999), and anaerobic activities are responsible for degradation and transformation below the oxic-anoxic interface (Zehnder and Stumm, 1988; Canfield et al., 1993; Meyers and Ishiwatari, 1993; Tranvik, 1998). The decomposition of organic matter continues under these conditions, but at a strongly reduced rate (Ishiwatari, 1985; Hatcher and Spiker, 1988; Stevenson, 1994; Hulthe et al., 1998). Microbial activities and chemical processes are responsible for the formation of humic substances, which, according to the biotic-condensation model and the biopolymer-degradation model, involves both polymerization and degradation (Hedges, 1988; Stevenson, 1994; McKnight and Aiken, 1998). The two models are not mutually exclusive; degradation is actually considered to be a preliminary stage or even a prerequisite for polymerization (Kemp and Johnston, 1979; Meyers and Ishiwatari, 1993). However, the relative contribution of both processes to the 
formation of humic substances in sediments is still under debate (Hedges, 1988; Ishiwatari, 1992).

Earlier investigations on the degradation and transformation of organic matter in sediments concentrated mainly on the soluble and low-molecular-weight fractions or included destructive or bulk-analyzing methods such as pyrolysis-GC-MS and NMR (Kemp and Johnston, 1979; Ishiwatari, 1985, 1992; Meyers and Ishiwatari, 1993). To arrive at a better understanding of the humification processes in sediments, it is necessary to describe depth-dependent changes in the high-molecular-weight fractions and to analyze quantitatively the different fractions of humic substances at a higher vertical resolution (Meyers and Ishiwatari, 1993).

In this study, we analyzed at high resolution the vertical distribution of different fractions of organic matter in freshwater lake sediments. We determined the sizeclass distribution of the soluble fractions with highpressure gel-permeation chromatography and characterized depth-related changes of the humic acids by elemental analysis, and IR-spectroscopy, and by thermal analysis of sediment samples.

\section{Materials and methods}

\subsection{Sampling of the sediment cores}

Profundal sediments of Lake Constance were sampled with a gravity corer at a depth of about $100 \mathrm{~m}$ from the research vessel 'Robert Lauterborn' at a sampling site near Güttingen (coordinates $47^{\circ} 37.86^{\prime} \mathrm{N}$ and $9^{\circ} 18.13^{\prime} \mathrm{E}$ ). Cores were stored at $4^{\circ} \mathrm{C}$ and processed within $12 \mathrm{~h}$. The cores were introduced vertically through a rubber-sealed opening into an anoxic glove-box, in which oxygen was removed catalytically with hydrogen (5\% in nitrogen). Sediment subsamples from various core depths were taken with plastic syringes, which were cut off at the tip and introduced into the core horizontally.

\subsection{Extraction of organic matter}

The classical method of solubility-based fractionation (Schnitzer and Khan, 1972) was used for isolation of the humic substances. Sediment samples $(10 \mathrm{~g})$ were extracted with $20 \mathrm{ml} \mathrm{NaOH}(0.1 \mathrm{M})$ in stainless-steel centrifuge tubes under an atmosphere of $\mathrm{N}_{2}$ at $30^{\circ}$ for $24 \mathrm{~h}$ on a rotary shaker. The extract was separated from the insoluble residue (humins and inorganic components) by centrifugation $(13,000 \times g, 30 \mathrm{~min})$. After acidification with $1 \mathrm{M} \mathrm{HCl}$ to $\mathrm{pH} 1$, the humic acids were allowed to precipitate for $24 \mathrm{~h}$ at $4{ }^{\circ} \mathrm{C}$, and separated from the acid-soluble supernatant by centrifugation $(13,000 \times g, 30 \mathrm{~min})$. After freeze-drying, the humic acids were stored at $4^{\circ} \mathrm{C}$ until analyzed; alkaline samples were kept under a nitrogen atmosphere.

\subsection{Quantification of organic matter}

The total organic carbon (TOC) content of the sediment was determined by wet chemical combustion and subsequent quantification of $\mathrm{CO}_{2}$ by flow injection analysis (FIA). Dried sediment $\left(0.1 \mathrm{~g}, 40^{\circ} \mathrm{C}\right.$ for $\left.8 \mathrm{~h}\right)$ was placed into the reaction shank of an $\mathrm{H}$-shaped tube containing a Teflon-coated magnetic stirrer bar, acidified with $2 \mathrm{ml} \mathrm{H}_{2} \mathrm{SO}_{4}(3 \mathrm{M})$ and stirred for $3 \mathrm{~h}$ under vacuum to remove the carbonates. $\mathrm{K}_{2} \mathrm{Cr}_{2} \mathrm{O}_{7}(2 \mathrm{ml}, 8 \%$ $(\mathrm{w} / \mathrm{v})$ in $5 \mathrm{M} \mathrm{H}_{2} \mathrm{SO}_{4}$ ) was added, and the tube was autoclaved for $2 \mathrm{~h}$ at $121^{\circ} \mathrm{C}$. After cooling to room temperature, $1 \mathrm{ml} \mathrm{NaOH}(0.5 \mathrm{M})$ was injected into the trapping shank of the tube to absorb the $\mathrm{CO}_{2}$. After $48 \mathrm{~h}$ of continuous stirring, the carbonate content was analyzed by FIA, using the diffusion cell described by Hall and Aller (1992) with a flow rate of carrier and receiving eluent $\left(20 \mathrm{mM} \mathrm{H}_{2} \mathrm{SO}_{4}\right.$ and $\left.10 \mathrm{mM} \mathrm{NaOH}\right)$ of $0.3 \mathrm{ml} \mathrm{min}^{-1}$. Carbonate ions were quantified using a conductivity detector.

Efficiency and reproducibility of the method were tested as described by $\mathrm{Ji}$ et al. (2000) with ${ }^{14} \mathrm{C}$-ringlabeled benzoic acid and with synthetic humic model compounds (Kappler et al., 2000).

\subsection{Chemical and spectroscopic analyses}

Prior to analysis, humic acids were dried under vacuum at $25^{\circ} \mathrm{C}$ and rehydrated at room temperature and ambient humidity. Carbon, hydrogen, and nitrogen (CHN) elemental content was determined with a $\mathrm{CHN}-$ O-rapid-analyzer (Heraeus, Hanau, Germany). Samples for IR spectroscopy were prepared by mixing $1 \mathrm{mg}$ of the humic acid preparations with $200 \mathrm{mg}$ oven-dried $\mathrm{KBr}\left(140^{\circ} \mathrm{C}\right)$ and the tablets were pressed under vacuum for $10 \mathrm{~min}$. The spectra were recorded using a Polaris FT-IR-spectrometer (Mattson Instruments, Madison, Wisc., USA).

Thermo-gravimetric analyses of dried sediment samples were carried out with a differential thermal analyzer (Netsch, Selb, Germany). The samples were heated to $800^{\circ} \mathrm{C}$ in a corundum crucible at a rate of $2^{\circ} \mathrm{C} \mathrm{min}^{-1}$. The reference material was platinum. During the measurements, the sample chamber was flushed with nitrogen.

For high-pressure gel-permeation chromatography (HP-GPC), the humic acid samples were dissolved in anoxic $0.1 \mathrm{M} \mathrm{NaOH}\left(1 \mathrm{mg} \mathrm{m} \mathrm{m}^{-1}\right)$. The acid-soluble supernatant obtained after the humic acid precipitation step, was analyzed directly. All samples were filtered (cellulose acetate, $0.22 \mu \mathrm{m}$ ), and $50-\mu \mathrm{l}$ aliquots were injected onto an HP-GPC column (length $25 \mathrm{~cm}$, diameter $8 \mathrm{~mm}$ ) filled with TSK HW $55 \mathrm{~S}$ gel (copolymer of ethylene glycol and methacrylate, particle diameter 20$40 \mu \mathrm{m}$, pore size $300 \AA$, Grom, Herrenberg, Germany). The exclusion limits of this material were 200,000 for dextranes and 700,000 for globular proteins. 
The HPLC system was equipped with a UV detector and an autosampler. The detection wavelength was 254 $\mathrm{nm}$; the mobile phase was $10 \mathrm{mM}$ sodium phosphate buffer $\mathrm{pH} 11\left(0.1 \mathrm{ml} \mathrm{min}^{-1}\right)$. To avoid autoxidation of the injected samples, the eluent was carefully degassed and kept under $\mathrm{N}_{2}$ during the measurements.

The column was calibrated with polyethylene glycol standards and showed a log-linear correlation between molecular weight and elution volume over a range from 200 to 300,000 . The molecular weight distribution of humic acids and of the residual acid-soluble supernatant was found to be largely concentration-independent in a range of 0.05 and $2 \mathrm{mg} / \mathrm{ml}$ (Kappler and Brune, 1999).

\section{Results}

\subsection{Depth profiles of sedimentary organic matter}

Multiple sediment cores were sampled at the same sampling site with a gravity corer and were subsampled for the determination of the individual parameters with the indicated depth resolution $(0.5-2 \mathrm{~cm})$. Fig. 1A shows the depth profile of the total organic carbon (TOC) content of $20-\mathrm{cm}$ sediment cores, which represent a time series reflecting the deposition of organic material over a period of about 100 years (Müller, 1966, 1997). TOC content was highest in the upper 8 centimeters of the cores and decreased steadily with further depth. The TOC content appears quite variable in the upper layer, which is largely due to the differences between the cores; the TOC in the individual cores was actually quite constant over the top 8 centimeters (not shown).

The humic acid content in the sediment decreased continuously, with a change in slope between 8 and $10 \mathrm{~cm}$, and the calculated TOC-to-HA ratio increased from 2.0 to 5.6 , with a distinct discontinuity between 8 and $10 \mathrm{~cm}$ (Fig. 1A). The acid-soluble supernatant, quantified by integration of the UV signal of the gel-permeation chromatograms, showed the highest values in the surface layer (0-2 cm depth), decreased rapidly within the upper $4 \mathrm{~cm}$ and remained relatively constant in deeper zones (Fig. 1B).

\subsection{Changes of elemental composition and peptide and carbohydrate content}

Depth-related analysis of the elemental composition of the humic acids extracted from different sediment depths showed an initial increase both in carbon and nitrogen content within the first $5 \mathrm{~cm}$ (Fig. 2A). The carbon content in the humic acids remained relatively constant between 5 and $12 \mathrm{~cm}$ depth, where it increased again sharply and remained relatively constant for the rest of the core. In contrast, the nitrogen content decreased continuously between 5 and $20 \mathrm{~cm}$, with a significant change of slope around $12 \mathrm{~cm}$ depth. The decreasing nitrogen content is reflected in an increasing $\mathrm{C} / \mathrm{N}$ atomic ratio, which also changes in slope around $12 \mathrm{~cm}$ depth (Fig. 2B). In addition, there was a small but significant decrease in the $\mathrm{C} / \mathrm{N}$ ratio from the surface layer to the next depth interval. The hydrogen content in the humic acids remained almost constant (5.8-6.1\%) over the whole depth range.

FT-IR spectra of humic acid preparations from different depth (Fig. 3) resembled typical spectra of lake humic acids published earlier by other authors (Ishiwatari, 1967). Especially the humic acids from the surface layer $(0-2 \mathrm{~cm})$ showed absorption bands at $1630-1640$ $\mathrm{cm}^{-1}$ and at $1510-1550 \mathrm{~cm}^{-1}$, indicating the presence of peptides (due to $\mathrm{C}=\mathrm{O}$ stretching and $\mathrm{N}-\mathrm{H}$ deformation

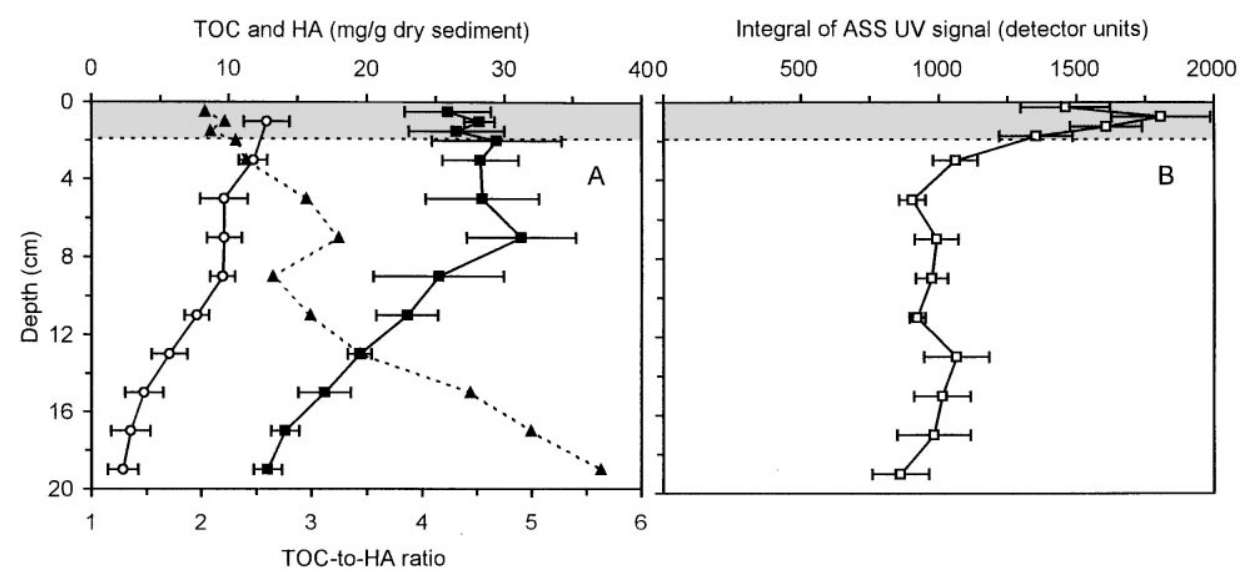

Fig. 1. (A) Depth profiles of total organic carbon (TOC, $\mathbf{\square})$, humic acids (HA, O) and TOC-to-HA ratio ( $\mathbf{(})$ ). (B) Depth profiles of the acid-soluble supernatant (ASS, $\square$ ) were obtained by integration of the UV signals (254 $\mathrm{nm})$ of the respective gel-permeation chromatograms (Fig. 5). Data are averages ( \pm S.D.) of three independently sampled cores from the same sampling site. The boundary between the surface layer $(0-2 \mathrm{~cm}$ depth), which coincides with the microbial oxygen- and nitrate-reducing zone, and the deeper sediment is indicated by a dotted line. 
of amidic linkages; Goh and Stevenson, 1971, Gomes et al., 1996), and an absorption band in the region of 950$1170 \mathrm{~cm}^{-1}$ (due to the $\mathrm{C}-\mathrm{O}$ stretching of carbohydrates, Niemeyer et al., 1992; Stevenson, 1994). With increasing depth, both the peptide and carbohydrate signal in the humic acids decreased.

\subsection{Depth-dependent changes of the thermal stability}

Thermo-gravimetric analysis under nitrogen of dried sediment samples from a single core showed that at all depths, the fraction of the stable organic matter (weight loss between 400 and $800^{\circ} \mathrm{C}$ ) is much larger than the fraction of the easily-decomposable organic matter (weight loss between 100 and $400^{\circ} \mathrm{C}$; Fig. 4). The fraction of stable organic matter increased within the first centimeters; with further depth, both fractions decreased slightly, reflecting the general decrease of the TOC (Fig. 1A). The ratio of the easily-decomposable organic matter to the more stable organic matter decreased markedly below the surface layer, remained relatively constant between 2 and $10 \mathrm{~cm}$
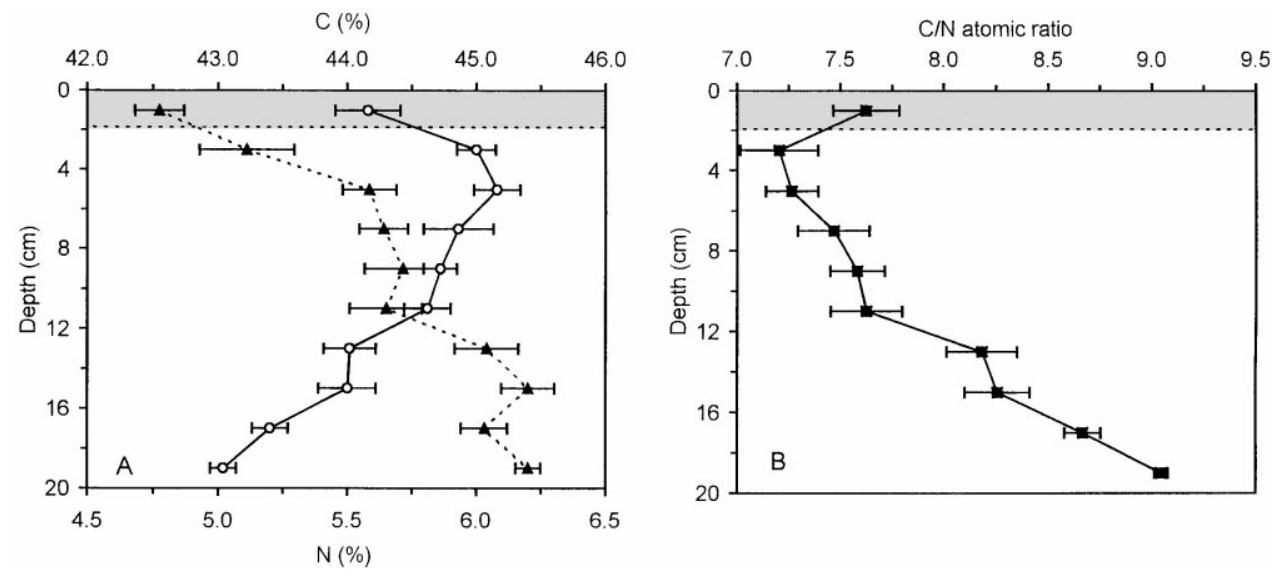

Fig. 2. Carbon $(\boldsymbol{\Delta})$ and nitrogen $(\mathrm{O})$ content $(\mathrm{A})$ and $\mathrm{C} / \mathrm{N}$ atomic ratio $(\mathrm{B})$ of humic acids extracted from sediment cores. Data are averages $( \pm$ S.D.) of three independently sampled cores. The boundary between the surface layer $(0-2 \mathrm{~cm}$ depth $)$ and the deeper sediment is indicated by a dotted line.

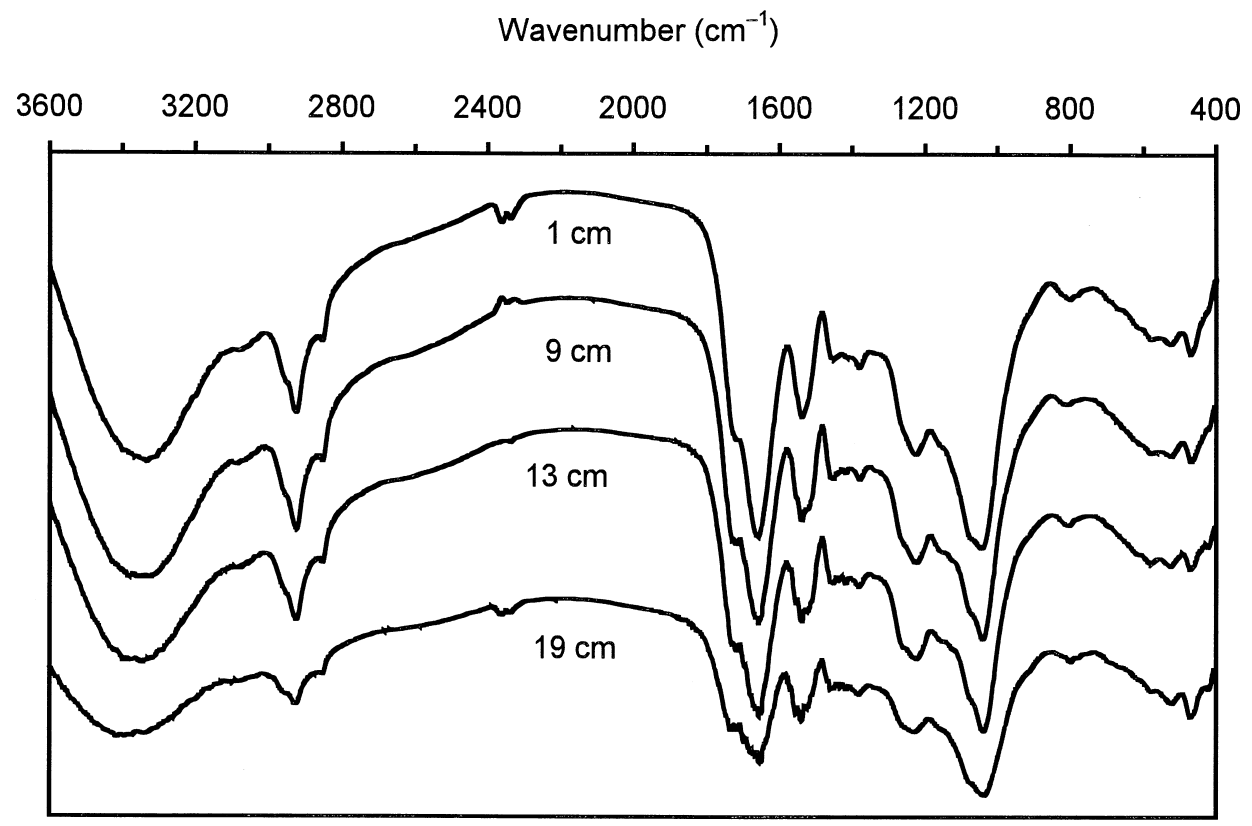

Fig. 3. Fourier-transform infrared (FT-IR) spectra of humic acids extracted from different sediment depths. The amount of humic acids was identical in each assay. 
depth, and dropped again slightly between 10 and $12 \mathrm{~cm}$ (Fig. 4).

\subsection{Changes in size-class distribution determined by HP-GPC}

Fig. 5 shows representative size-class distribution profiles of humic acid preparations and the respective acid-soluble supernatants of core samples from a depth of 3-4, 11-13 and 17-19 cm, illustrating the changes observed with increasing depth. Quantitative analysis of the size-class fractions (as defined in Fig. 5) within the humic acid preparations indicated that the proportion of molecules with high molecular weight (HMW fraction), which showed the highest percentage immediately below the surface layer, decreases with depth (Fig. 6). Concomitantly, the retention time of the peak maximum of the most abundant medium molecular weight (MMW) fraction increases (Fig. 5), indicating a shift towards lower molecular weight. This was confirmed by the quantitative analysis of the MMW fraction, which was lowest immediately below the surface layer and increased with depth, forming the mirror image of the HMW fraction. In contrast, the small fraction of molecules with low molecular weight (LMW fraction) of the humic acid preparations changed only slightly with depth.

Within the acid-soluble supernatant, changes in molecular size distribution occurred mainly in the top $10 \mathrm{~cm}$ of the sediment core (Fig. 6). The peak maximum

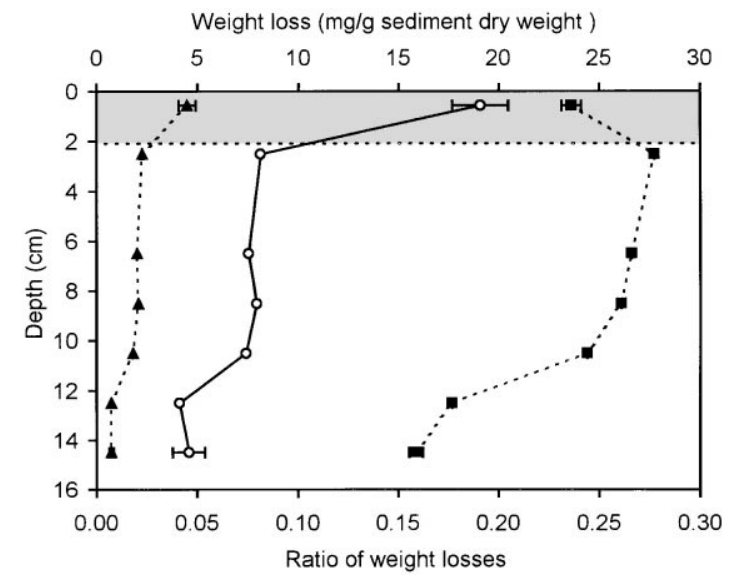

Fig. 4. Depth profile of the weight loss of dried sediment samples between 100 and $400^{\circ} \mathrm{C}(\boldsymbol{\Delta})$ and 400 and $800^{\circ} \mathrm{C}(\boldsymbol{\square})$ and the resulting ratios of weight losses $\left[\left(100-400^{\circ} \mathrm{C}\right) /\left(400-800^{\circ} \mathrm{C}\right)\right]$ $(\bigcirc)$. Thermal analysis was performed under nitrogen. Data for one core only, but results for independent samples $(0-2 \mathrm{~cm}$ and $14-16 \mathrm{~cm}$ depth) from two other cores were included (represented by the error bars) to illustrate the deviation between the cores. The boundary between the surface layer $(0-2 \mathrm{~cm}$ depth) and the deeper sediment is indicated by a dotted line. of the most abundant MMW fraction was shifted slightly, but reproducibly, to shorter retention time with increasing distance from the sediment surface, indicating an increasing molecular weight (Fig. 5). Quantitative analysis of the MMW fraction showed that the relative proportion of this fraction decreases within the top centimeters and increases again with depth (Fig. 6). In contrast, the relative proportion of the LMW fraction, which was much more abundant in the acid-soluble supernatant than in the humic acid preparations, first increases in the top layer and decreases again with depth to the initial values. The HMW fraction of the acidsoluble supernatant accounted for less than $5 \%$ and showed only slight changes with depth.

\section{Discussion}

In sediments with a permanent deposition of organic matter on the sediment surface, microbial activity leads to a characteristic layering that reflects the sequence of electron acceptors according to the thermodynamic properties of the corresponding redox processes (Zehnder and Stumm, 1988; Schink, 1999). Oxygen is consumed within a few millimeters, and anaerobic respiration and fermentation processes are responsible for the degradation and mineralization of organic matter. The defined and stable layering is particularly evident in undisturbed profundal sediments like those investigated in this study and allows a direct correlation of depth-related changes of organic matter to time-dependent transformation, degradation, and mineralization processes.

Earlier studies with lake sediments showed a general decrease of the organic matter content with depth (Kemp and Johnston, 1979; Ishiwatari, 1985; Meyers and Ishiwatari, 1993), accompanied by transformations of the more soluble and smaller-sized fulvic and humic acids to insoluble humins (Bourbonniere and Meyers, 1978; Rea et al., 1980; Ishiwatari, 1985; Hatcher and Spiker, 1988). Our results from profundal sediments of Lake Constance showed that the TOC content decreases strongly between 8 and $20 \mathrm{~cm}$ depth. However, in the top $8 \mathrm{~cm}$ (corresponding to about 20-40 years of organic matter deposition, Müller, 1966, 1997), the TOC remains almost constant. At a constant sedimentation rate, one would expect the TOC to decrease with depth due to the presence of high microbial activities, especially in the upper sediment layers (Brune et al., 2000). The fact that the TOC content in the upper 8 $\mathrm{cm}$ of the sediment remains quite constant is probably related to the decrease of eutrophication of Lake Constance during the last 40 years (Stabel, 1998), which caused a decreasing deposition of organic matter onto the sediment surface.

Nevertheless, the ratio of TOC to HA increased significantly within the top $8 \mathrm{~cm}$ of the sediment core. 


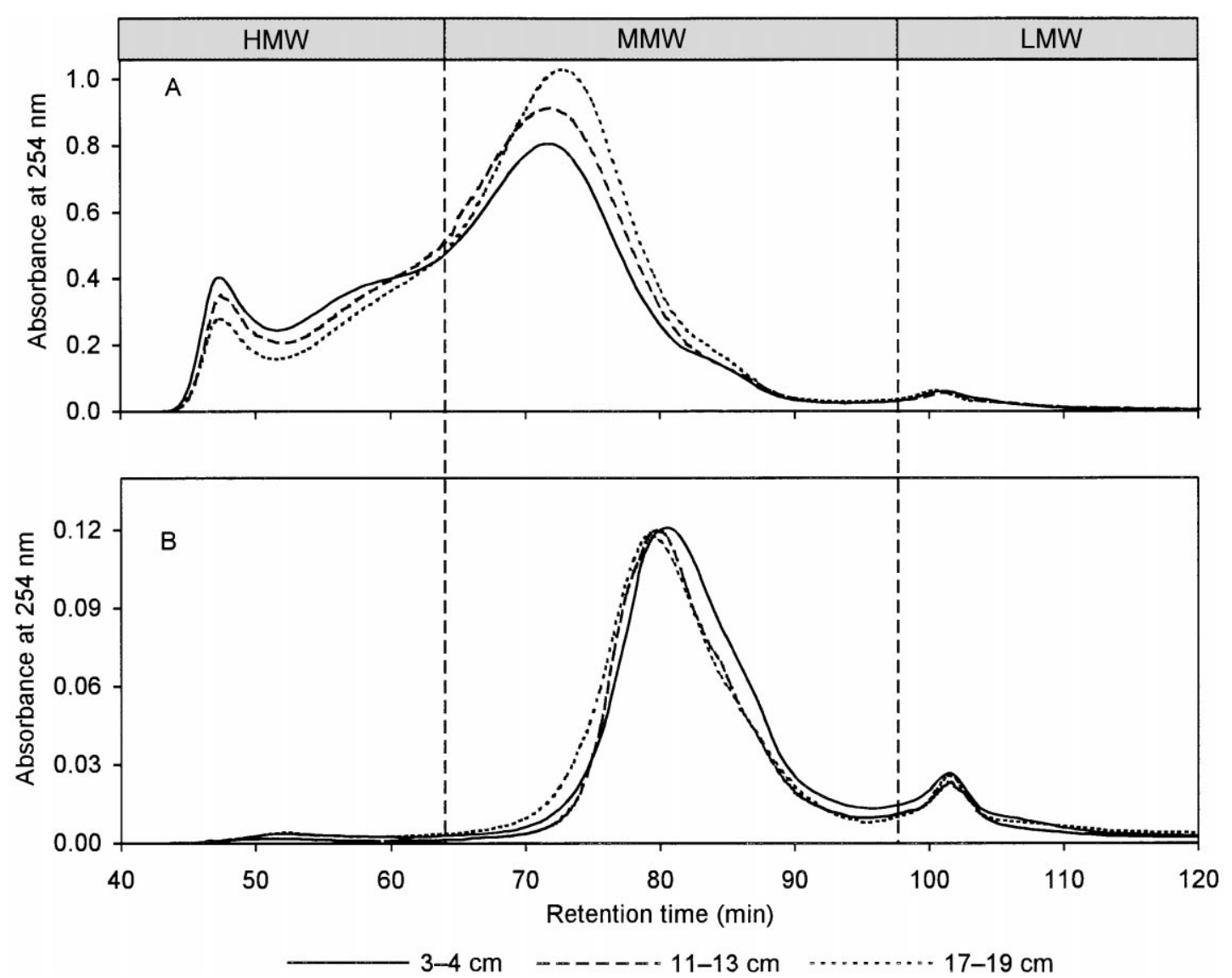

Fig. 5. Typical gel-permeation chromatograms of humic acid preparations (A) and of the corresponding acid-soluble supernatants (B), illustrating the differences in size-class distribution at different depths below the sediment surface. High-molecular-weight (HMW), medium-molecular-weight (MMW), and low-molecular-weight (LMW) fractions were arbitrarily defined by the retention times of polyethylene glycol standards $\left(M_{\mathrm{r}}=80,000\right.$ and 500). The chromatograms of the acid-soluble supernatants were normalized by area for better comparison.
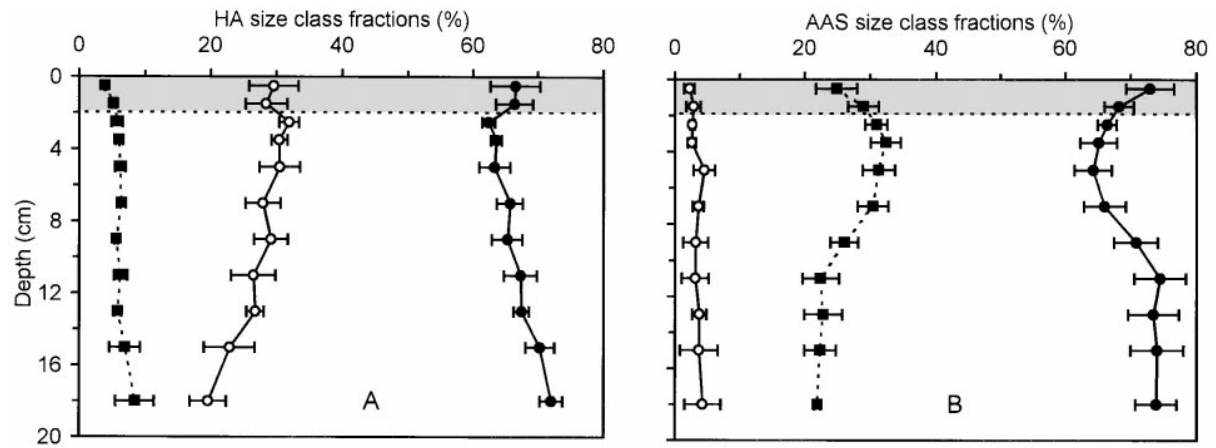

Fig. 6. Depth-dependent size-class distribution in the humic acid fraction (A) and acid-soluble supernatant (B) determined by HPGPC. The size-class boundaries indicated in Fig. 5 were used for analysis of the high-molecular-weight (HMW, $\bigcirc$ ), medium-molecular-weight $(\mathrm{MMW}, \mathbf{0})$ and low-molecular-weight $(\mathrm{LMW}, \mathbf{\square})$ fractions. Averages \pm S.D. of four independently sampled cores are given. The boundary between the surface layer $(0-2 \mathrm{~cm}$ depth) and the deeper sediment is indicated by a dotted line. 
Concomitantly, the thermal stability of the organic matter in the sediment increased from the surface layer $(0-2 \mathrm{~cm})$ to the deeper sediment zone, whereas the amount of humic acids and of organic matter in the acid-soluble supernatant decreased with depth. This indicates a clear shift from the freshly deposited organic matter on the sediment surface to more humified material with increasing distance from the sediment surface. Thermal stability analysis and the TOC-to-HA ratio showed that the main stabilization processes occur within the surface layer $(0-2 \mathrm{~cm}$ depth), which corresponds to the layer of microbial oxygen and nitrate reduction (S. Hauck, M. Benz, A. Brune and B. Schink, unpublished results). Another transition zone seems to be present between 8 and $12 \mathrm{~cm}$ depth, indicated by distinct changes in the TOC-to-HA and $\mathrm{C} / \mathrm{N}$ ratios, the thermal stability data, and the size distribution patterns of organic matter. There is currently no satisfying explanation for this phenomenon, but it may be related to changes in the quantity (and possibly quality) of organic input caused by the decrease of eutrophication of Lake Constance starting about 40 years ago (Stabel, 1998).

The depth-dependent decrease of molecular weight in both humic acids and the acid-soluble supernatant, together with the net degradation of organic matter and the increased thermal stability and TOC-to-HA ratio, supports the theory that in lake sediments both degradation and condensation reactions are involved in the humification of organic matter (Hatcher and Spiker, 1988; Hedges, 1988; Ishiwatari, 1992).

Significant microbial degradation of organic matter occurs already within the water column (Meyers and Ishiwatari, 1993). However, peptides, carbohydrates and other organic compounds of high molecular weight are adsorbed to metal oxides and mineral particles within the water column (Gloor et al., 1981), which protects them against degradation and leads to an enrichment of molecules of higher molecular weight on the sediment surface. Infrared absorption spectra and $\mathrm{C} / \mathrm{N}$ atomic ratios of humic acids obtained in this study indicate a decrease in peptide and carbohydrate content of the sediment with depth, confirming earlier results of others (Ishiwatari, 1972; Kemp and Johnston, 1979; Hatcher et al., 1982; Fichez, 1991). At 18-20 cm depth, IR signals still indicated the presence of peptidic nitrogen, possibly stabilized by binding or adsorption mechanisms (Steinberg and Muenster, 1985) or by encapsulation processes (Knicker and Hatcher, 1997).

This study shows an increasing degree of humification of the sediment organic matter with depth. The humification includes degradation and polymerization processes and the highly-resolved depth profiles allow the surface layer $(0-2 \mathrm{~cm}$ depth), where the main stabilization processes occur, to be distinguished from the deeper sediment. Further studies will address the role of humic substances as electron acceptors in microbial redox processes and as mediators of electron transport to insoluble iron species at different sediment depths.

\section{Acknowledgements}

The authors thank Gerhard Wildermuth who helped in performing the thermo-gravimetric analysis of the sediment samples. The research was supported by the Deutsche Forschungsgemeinschaft.

\section{Associate Editor - J.A. Rice}

\section{References}

Bourbonniere, R.A., Meyers, P.A., 1978. Characterization of sedimentary humic matter by elemental and spectroscopic methods. Canadian Journal of Spectroscopy 23, 35-41.

Brune, A., Frenzel, P., Cypionka, H., 2000. Life at the oxicanoxic interface: microbial activities and adaptations. FEMS Microbiology Reviews 24, 691-710.

Canfield, D.E., Thamdrup, B., Hansen, J.W., 1993. The anaerobic degradation of organic matter in Danish coastal sediments: iron reduction, manganese reduction, and sulfate reduction. Geochimica et Cosmochimica Acta 57, 3867-3883.

Fichez, R., 1991. Composition and fate of organic matter in submarine cave sediments; implications for the biogeochemical cycle of organic carbon. Oceanologica Acta 14, 369-377.

Gloor, R., Leidner, H., Wuhrmann, K., Fleischmann, T.H., 1981. Exclusion chromatography with carbon detection (A tool for further characterization of dissolved organic carbon). Water Research 15, 457-462.

Goh, K.M., Stevenson, F.J., 1971. Comparison of infrared spectra of synthetic and natural humic and fulvic acids. Soil Science 112, 392-400.

Gomes, R.C., Mangrich, A.S., Coelho, R.R.R., Linhares, L.F., 1996. Elemental, functional group and infrared spectroscopic analysis of actinomycete melanins from Brazilian soils. Biology and Fertility of Soils 21, 84-88.

Hall, P.O.J., Aller, R.C., 1992. Rapid, small-volume, flow injection analysis for $\mathrm{CO}_{2}$ and $\mathrm{NH}_{4}^{+}$in marine and freshwaters. Limnology and Oceanography 37, 1113-1119.

Hatcher, P.G., Simoneit, B.R.T., Mackenzie, F.T., Neumann, A.C., Thorstenson, D.C., Gerchakov, S.M., 1982. Organic geochemistry and pore water chemistry of sediments from Mangrove lake, Bermuda. Organic Geochemistry 4, 93-112.

Hatcher, P.G., Spiker, E.C., 1988. Selective degradation of plant biomolecules. In: Frimmel, F.H., Christman, R.F. (Eds.), Humic Substances and their Role in the Environment. Wiley, New York, pp. 59-74.

Hedges, J.I., 1988. Polymerization of humic substances in natural environments. In: Frimmel, F.H., Christman, R.F. (Eds.), Humic Substances and their Role in the Environment. Wiley, New York, pp. 45-58.

Hulthe, G., Hulth, S., Hall, P.O.J., 1998. Effect of oxygen on degradation rate of refractory and labile organic matter in continental marine sediment. Geochimica et Cosmochimica Acta 62, 1319-1328.

Ishiwatari, R., 1967. Infrared absorption band at $1540 \mathrm{~cm}^{-1}$ of 
humic acid from a recent lake sediment. Geochemical Journal 1, 61-70.

Ishiwatari, R., 1972. Transformation of sedimentary humic acids, facts and speculations. Proceedings from the International Meeting for Humic Substances. Pudoc, Wageningen, pp. 109-121.

Ishiwatari, R., 1985. Geochemistry of humic substances in lake sediments. In: Aiken, G.R., McKnight, D.M., Wershaw, R.L., MacCarthy, P. (Eds.), Humic Substances in Soil, Sediment, and Water. Geochemistry, Isolation, and Characterization. Wiley, New York, pp. 147-180.

Ishiwatari, R., 1992. Macromolecular material (humic substances) in the water column and sediments. Marine Chemistry $39,151-166$.

Ji, R., Kappler, A., Brune, A., 2000. Transformation and mineralization of synthetic ${ }^{14} \mathrm{C}$-labeled humic model compounds by soil-feeding termites. Soil Biology and Biochemistry $32,1281-1291$.

Kappler, A., Brune, A., 1999. Influence of gut alkalinity and oxygen status on mobilization and size-class distribution of humic acids in the hindgut of soil-feeding termites. Applied Soil Ecology 13, 219-2290.

Kappler, A., Ji, R., Brune, A., 2000. Synthesis and characterization of specifically ${ }^{14} \mathrm{C}$-labeled humic model compounds for feeding trials with soil-feeding termites. Soil Biology and Biochemistry 32, 1271-1280.

Kemp, A.L.W., Johnston, L.M., 1979. Diagenesis of organic matter in the sediments of Lake Ontario. Journal of Great Lakes Research 5, 1-10.

Knicker, H., Hatcher, P.G., 1997. Survival of protein in an organic-rich sediment: possible protection by encapsulation in organic matter. Naturwissenschaften 84, 231-234.

McKnight, D.M., Aiken, G.R., 1998. Sources and age of aquatic humic substances. In: Hessen, D.O., Tranvik, L.J. (Eds.), Aquatic Humic Substances: Ecology and Biogeochemistry. Springer, Berlin, pp. 259-284.

Meyers, P.A., Ishiwatari, R., 1993. Lacustrine organic geochemistry - an overview of indicators of organic matter sources and diagenesis in lake sediments. Organic Geochemistry 20, 867-900.

Müller, G., 1966. Die Sedimentbildung im Bodensee. Naturwissenschaften 10, 237-247.

Müller, G., 1997. Nur noch geringer Eintrag anthropogener Schwermetalle in den Bodensee - neue Daten zur Entwicklung der Belastung der Sedimente. Naturwissenschaften 84, 37-38.

Niemeyer, J., Chen, Y., Bollag, J.-M., 1992. Characterization of humic acids, composts and peat by diffuse reflectance fourier-transform infrared spectroscopy. Soil Science Society of America Journal 56, 135-140.

Rea, D.K., Bourbonniere, R.A., Meyers, P.A., 1980. Southern Lake Michigan sediments: changes in accumulation rate, mineralogy, and organic content. Journal of Great Lakes Research 6, 321-330.

Schink, B., 1999. Habitats of Prokaryotes. In: Lengeler, J.W., Drews, G., Schlegel, H.G. (Eds.), Biology of the Prokaryotes. Thieme, Stuttgart, pp. 763-803.

Schnitzer, M., Khan, S.U., 1972. Humic Substances in the Environment. Marcel Dekker, New York.

Stabel, H.-H., 1998. Chemical composition and drinking water quality of the water from Lake Constance. Arch. Hydrobiol. Spec. Issues Advanc. Limnol 53, 13-30.

Steinberg, C., Muenster, U., 1985. Geochemistry and ecological role of humic substances in lakewater. In: Aiken, G.R., McKnight, D.M., Wershaw, R.L., MacCarthy, P. (Eds.), Humic Substances in Soil, Sediment, and Water. Geochemistry, Isolation, and Characterization. Wiley, New York, pp. 105-146.

Stevenson, F.J., 1994. Humus Chemistry. Genesis, Composition, Reactions, 2nd Edition. Wiley, New York.

Tranvik, L.J., 1998. Degradation of dissolved organic matter in humic waters by bacteria. In: Hessen, D.O., Tranvik, L.J. (Eds.), Aquatic Humic Substances: Ecology and Biogeochemistry. Springer, Berlin, pp. 9-40.

Zehnder, A.J.B., Stumm, W., 1988. Geochemistry and biogeochemistry of anaerobic habitats. In: Zehnder, A.J.B. (Ed.), Biology of Anaerobic Microorganisms. Wiley, New York, pp. 1-38. 